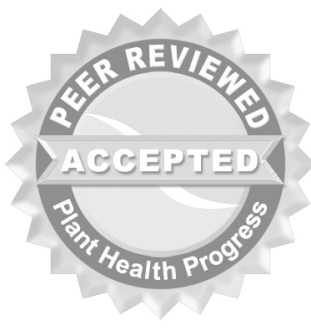

(C) 2013 Plant Management Network.

Accepted for publication 17 April 2013. Published 29 July 2013.

\title{
A Photographic Diagnostic Guide for Identification of the Principal Cranberry Fruit Rot Pathogens
}

\author{
Lindsay D. Wells and Patricia S. McManus, Department of Plant \\ Pathology, University of Wisconsin, Madison, WI 53706
}

Corresponding author: Patricia S. McManus. psm@plantpath.wisc.edu

Wells, L. D., and McManus, P. S. 2013. A photographic diagnostic guide for identification of the principal cranberry fruit rot pathogens. Online. Plant Health Progress doi:10.1094/PHP2013-0729-01-DG.

\section{Introduction}

The large American cranberry (Vaccinium macrocarpon Aiton) is native to parts of eastern North America and is economically important in Massachusetts, Michigan, New Jersey, and Wisconsin, as well as several eastern Canadian provinces and the North American Pacific Northwest. The farm gate values of cranberry ranged from $\$ 298$ to $\$ 344$ million and from $\$ 70$ to $\$ 88$ million in the United States and Canada, respectively from 2010 to $2011(14,16)$. When cranberry cultivation first began in the early nineteenth century, growers were able to produce cranberries for 5 to 10 years until the fruit succumbed to the "the rot" (10). Modern cultural methods and fungicides allow plantings to remain productive for several decades, but cranberry fruit rot remains the most devastating disease problem, especially in warmer growing regions where crop losses approach $100 \%$ if fruit rot is left unchecked $(10,11)$.

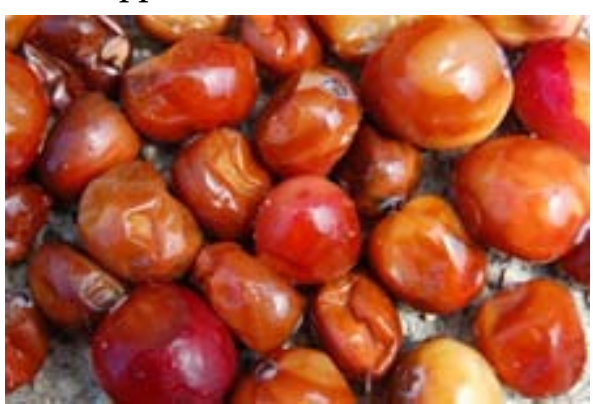

Fig. 1. Soft, rotten cranberry fruit with epidermal discoloration.
As many as 15 fungal species contribute to the cranberry fruit rot disease complex $(9,10,11)$, although the most significant economic losses can be attributed to a subset of five to seven species, depending on geographic region. Although rotten cranberry fruit take on various symptoms (Fig. 1), determining the pathogen(s) involved is not possible by viewing symptoms alone. Rather, plant disease diagnosticians and fruit pathology laboratories culture rotten cranberries on different microbiological media to isolate and identify the cranberry fruit rot pathogens. It is very common to isolate more than one pathogen from a rotten berry, but in such cases the role of each pathogen in causing rot is not known. These pathogens differ in colony appearance when grown on different types of microbiological media, making it difficult for diagnosticians to share descriptions of colony morphology. Moreover, many university-based laboratories undergo frequent personnel changes which make training difficult. Thus, the objective of this report is to provide a photographic identification guide for each of the seven principal fruit rot pathogens when grown on different microbiological media. Our intent is that the photographs will supplement, but not replace, descriptions of pathogens provided in the Compendium of Blueberry and Cranberry Diseases (7).

Host: Large American cranberry (Vaccinium macrocarpon Aiton)

Diseases and Pathogens

Cranberry fruit rot can be categorized into field rot (i.e., rot occurring in the field prior to harvest); and storage rot (i.e., rot occurring in storage after harvest), based upon timing of disease development. Most cranberries are grown for processing and are frozen within hours of harvest; storage rot is of little 
concern to these growers. However, field rot is a concern for all cranberry growers. Common names of the most important field rot diseases and the causal agents are listed in Table 1. These pathogens are deemed important because of their prevalence in different cranberry growing regions.

While detailed life cycles are not well known for all of these pathogens $(10,13)$, Koch's postulates have been completed for the pathogens most commonly associated with fruit rot, and their role(s) in contributing to cranberry fruit rot have been confirmed $(1,2,3,4,5,6,10,15,17,18)$.

Table 1. Disease names and fungal pathogens involved in the field rot of cranberry fruit.

\begin{tabular}{|c|c|c|}
\hline $\begin{array}{c}\text { Disease common } \\
\text { name }\end{array}$ & $\begin{array}{c}\text { Pathogen scientific } \\
\text { name (anamorph) }\end{array}$ & $\begin{array}{c}\text { Pathogen scientific } \\
\text { name (teleomorph) }\end{array}$ \\
\hline Bitter Rot & Colletotrichum acutatum & Glomerella acutata \\
\hline Bitter Rot & $\begin{array}{c}\text { Colletotrichum } \\
\text { gloeosporioides }\end{array}$ & Glomerella cingulata \\
\hline $\begin{array}{c}\text { Berry Speckle/ } \\
\text { Botryosphaeria fruit rot }\end{array}$ & Phyllosticta elongata & BotryosphaeriaVvaccinii \\
\hline Early Rot & Phyllosticta vaccinii & \begin{tabular}{c} 
Guignardia vaccinii \\
\hline Blotch Rot
\end{tabular} \\
\hline $\begin{array}{c}\text { Viscid Rot/ } \\
\text { Upright Dieback }\end{array}$ & Phomopsis vaccinii & $\begin{array}{c}\text { Physalospora vaccinii } \\
\text { (formerly }\end{array}$ \\
\hline Ripe Rot & Coleophoma empetri & Diaporthe vaccinii \\
\hline
\end{tabular}

$\mathrm{x}$ Anamorph or teleomorph not known.

y Molecular studies indicate that the teleomorph has been misplaced in Botryosphaeria (19), but this remains the officially assigned teleomorph.

\section{Symptoms and Signs}

Cranberry fruit rot refers simply to any berry showing rot symptoms (Fig. 1), regardless of the causal agent (10). Rotten fruit usually have watery spots with softened pericarp tissues. Lesions on mature berries are lighter in color than the surrounding healthy tissue, and the epidermal tissue within the lesions often is translucent, becoming darker in color as the rot progresses. Occasionally fungal fruiting bodies will form on the surface of the berries. Typically cranberry fruit rot diagnostics requires isolation and identification of fungi from symptomatic fruit on microbiological media.

\section{Geographic Range}

Cranberry fruit rot pathogens are found in all cranberry-growing regions of the United States and Canada, namely the Northeast, Midwest, and the Pacific Northwest of the United States, and British Columbia, Ontario, Quebec, and the Maritime Provinces of Canada. Coleophoma empetri, Colletotrichum acutatum, Colletotrichum gloeosporioides, and Phyllosticta vaccinii are genetically uniform in all cranberry-growing regions in North America, as determined by sequence analysis of the nuclear internal transcribed spacer (ITS) region (11). Thus, it is possible that the movement of cranberry material between growing regions is responsible for the introduction of these fungal pathogens to new areas (11).

\section{Pathogen Isolation and Identification}

Cranberries showing rot symptoms were collected throughout the 2010 and 2011 growing seasons from various cultivars and several sites in the major cranberry-growing region of central Wisconsin. Whole berries were surface disinfested for $5 \mathrm{~min}$ in a 10\% household bleach solution (final concentration $0.6 \%$ sodium hypochlorite) containing one drop of Tween 80 per $100 \mathrm{ml}$ of 
solution. Berries were then rinsed twice in sterile deionized water and sliced in half transversely. Each cranberry half was placed cut-side down onto a Petri plate containing potato dextrose agar (PDA) amended with streptomycin sulfate $(100 \mu \mathrm{g} / \mathrm{ml})$ to prevent bacterial growth. Four cranberry halves (i.e., two berries) were placed in each 90-mm Petri plate and incubated at room temperature (20 to $25^{\circ} \mathrm{C}$ ) for 2 weeks under indirect fluorescent light.

After 2 weeks, fungi growing in each plate were identified using morphological characteristics of the colonies, spores, and fruiting bodies (7). While some fungi (e.g., Colletotrichum spp.) sporulate within 1 week, others (e.g., Phomopsis vaccinii) require at least 2 weeks. Subcultures were made from representative samples of each of the seven principal cranberry fruit rot fungal pathogens (Table 1). Plugs cut from the margins of colonies were placed onto: (i) potato dextrose agar (PDA) [24 g potato dextrose broth (Acumedia, Lansing, MI), 16 g granulated agar (Fisher Scientific, Fair Lawn, NJ), and 1 liter of deionized $\mathrm{H}_{2} \mathrm{O}$ amended with streptomycin sulfate $\left.(100 \mu \mathrm{g} / \mathrm{ml})\right]$; (ii) V8 juice agar (200 ml of V8 juice, $2 \mathrm{~g}$ of $\mathrm{CaCO}_{2}, 15 \mathrm{~g}$ of agar, and $800 \mathrm{ml}$ of deionized $\mathrm{H}_{2} \mathrm{O}$ ); and (iii) corn meal agar (17 g dehydrated corn meal agar, Difco, Detroit, $\mathrm{MI}$, and 1 liter of deionized $\mathrm{H}_{2} \mathrm{O}$ ). Fungi were grown at room temperature (20 to $25^{\circ} \mathrm{C}$ ) under indirect fluorescent light for 16 days. Photographs of each fungus on the three types of microbiological media were then taken using a Nikon D40 camera under direct fluorescent lighting on a copy stand. Photographs on the left side of the figures show the fungal cultures as they appear from the top of the Petri plate. Photographs on the right side of the figures show the fungal cultures as they appear from the underside of the Petri plate.

Many of these fungal pathogens have fast growth rates, covering the surface of the culture medium after 16 days of growth at room temperature (see Figs. 29). Many of these fungi closely resemble one another during the early stages of growth, making it necessary to allow cultures to grow until distinguishable characteristics become evident (approximately 2 weeks). In addition to descriptions of spore and fruiting body morphology and size provided in the Compendium of Blueberry and Cranberry Diseases (7), some key features of colony morphology useful for identifying each of the fruit rot pathogens are as follows.

Coleophoma empetri (Fig. 2): Mycelia are initially white but eventually turn dark brown to black as the fungus matures, after approximately 9 days on V8 juice agar or corn meal agar. When grown in pure culture on potato dextrose agar, it often takes more than 2 weeks for mycelia to darken completely. Generally, cultures of Coleophoma growing out of fruit will become dark in color more quickly than cultures growing alone on microbiological medium. Coleophoma has a growth rate similar to that of Phyllosticta elongata, neither fast nor slow in comparison to other fruit rot pathogens. Dark brown to black mycelia are initially fluffy and slightly raised, becoming more appressed and smooth with age. Margins of the colonies are often smooth, shiny, and lobed. Pycnidia are sometimes produced in culture, forming rings near the outer edges of colonies. When rotten cranberry halves are in culture, pycnidia are formed along the edges of the fruit at the point of contact with the medium. Pycnidial development usually occurs more quickly on fruit than on media without fruit.

Colletotrichum acutatum (Fig. 3): Mats of aerial mycelia are initially white in color, but these hyphae quickly take on a pinkish-orange hue, producing pink to red pigmentation in the medium. Growth rate is very fast, and a colony will cover the surface of the culture medium within 2 weeks. Salmon-colored conidial masses are readily produced in culture as well as on surfaces of cultured rotten fruit. Setae are sometimes present on surfaces of cultured rotten fruit.

Colletotrichum gloeosporioides (Fig. 4): Colonies of C. gloeosporioides resemble those of $C$. acutatum during the early growth stages. Aerial hyphae are initially white to light gray in color and become darker gray in color with age. Growth rate is very fast (slightly faster than the growth rate of $C$. acutatum), but colonies of $C$. gloeosporioides lack the diffusion of red pigment in the media that is commonly observed in cultures of C. acutatum. Small immature ascomata 
embedded within the medium are visible from the underside of the plate. Setae are generally not present in these colonies. Masses of pale salmon-colored conidia are produced in culture as well as on the surfaces of the cultured rotten fruit.

Phomopsis vaccinii (Fig. 5): White mycelia are formed initially, which are closely appressed to the surface of the medium. As the fungus matures, mycelia darken until they are grayish in color, and patches of white aerial mycelia form. Pycnidia are readily produced in culture and on surfaces of cultured berries, a key feature to distinguish Phomopsis from the light strain of Physalospora. Conidia (both alpha and beta) are exuded from pycnidia in string-like, creamcolored cirri. The growth rate is fast (i.e., similar to that of Colletotrichum spp.), and growth rings are often formed on PDA as the culture grows. Colonies of Phomopsis closely resemble those of the light strain of Physalospora, often making it necessary to incubate colonies until conidia are formed, which usually occurs within 2 weeks. Sporulation occurs more quickly on fruit than on media without fruit.

Phyllosticta elongata (Fig. 6): Colonies are greenish-gray in color with appressed mycelia. Growth is often non-uniform. When this fungus first begins to grow, it is very similar in appearance to the early growth stages of Phyllosticta vaccinii, but $P$. elongata quickly (i.e., within a few days) becomes

distinguishable from this related fungus both in morphological characteristics as well as its faster growth rate compared to $P$. vaccinii.

Phyllosticta vaccinii (Fig. 7): Cultures are very slow growing in comparison to all of the other fruit rot pathogens, often reaching just 1 to $2 \mathrm{~cm}$ in diameter after 2 weeks. Colonies have mycelia that are dark olive to black in color and are slightly raised with irregular margins. Growth is often nonuniform, and the fungus frequently embeds itself into the medium, creating an uneven, bumpy appearance on the surface of the medium. Slimy cream-colored conidial masses are often produced in culture after approximately 2 to 3 weeks of incubation.

Physalospora vaccinii (Figs. 8 and 9): Two strains of this fungus are isolated from rotten cranberry fruit: a "dark" strain and a "light" strain (6). The dark strain produces gray to brownish-gray appressed mycelia in culture. The light strain has a similar appearance, but produces white mycelia. Growth of this fungus in culture often results in segmentation, with pigmentation differing within a single culture. The light strain of Physalospora is more frequently isolated from rotten cranberry fruit in Wisconsin and New Jersey than from other growing regions. Perithecia, formed both on the microbiological medium and on the surfaces of cultured rotten cranberries, produce ascospores. Ascospores are forcibly ejected from the perithecia, and with low-power magnification, germinating ascospores forming appressoria can often be observed scattered on lids of the Petri plates. Colonies of Physalospora grow at a rate between that of Colletotrichum spp. and Phyllostica vaccinii, and often grow in an irregular pattern.

\section{Summary}

The photographic guide presented here is for individuals identifying fruit rot pathogens isolated from cranberry fruit or other plant tissues. The photos are meant to provide examples of representative cultures of each fungal species and to supplement descriptions of spore morphologies reported in the Compendium of Blueberry and Cranberry Diseases (7). The form of each fungus that is most frequently isolated from cranberry tissue in Wisconsin is shown. Although many colonies of each fungal species are morphologically similar, variations in pigmentation and spore production between isolates exist. Molecular analysis can be completed for any isolates that cannot successfully be identified using morphological characteristics, using methods described elsewhere (12). Correct identification of fruit rot pathogens is essential for administering appropriate control recommendations. 


\section{Coleophoma empetri on potato dextrose agar}

amended with streptomycin sulfate
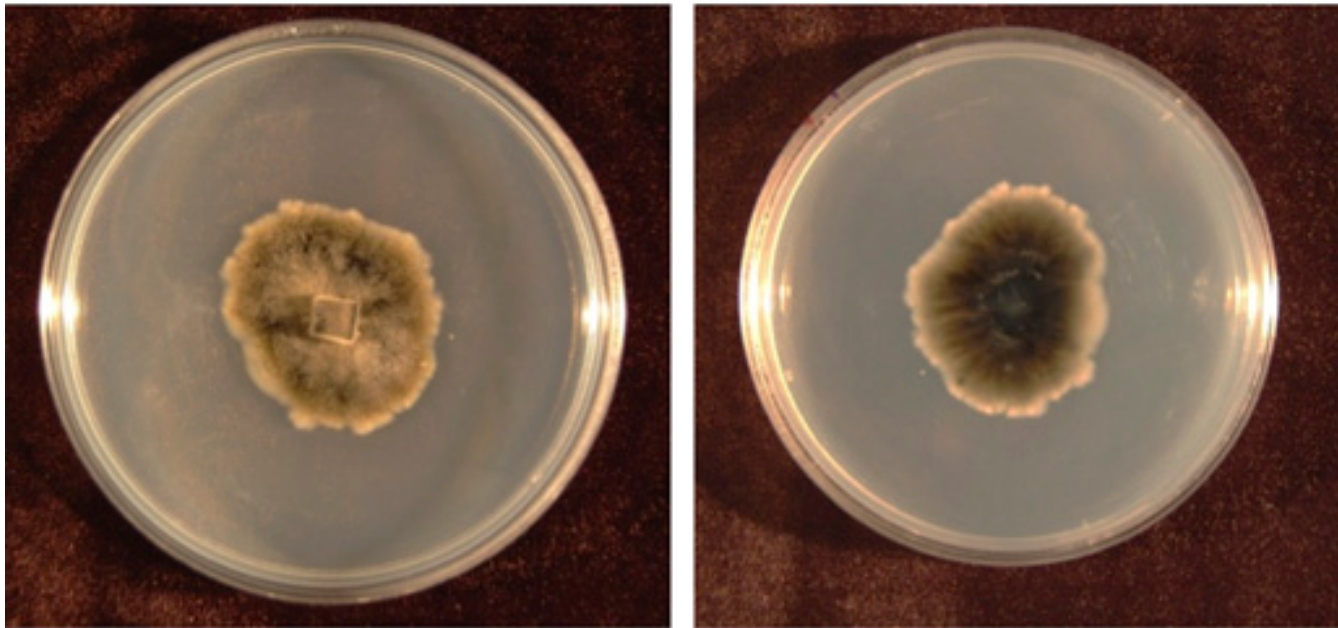

Coleophoma empetri on V8 juice agar
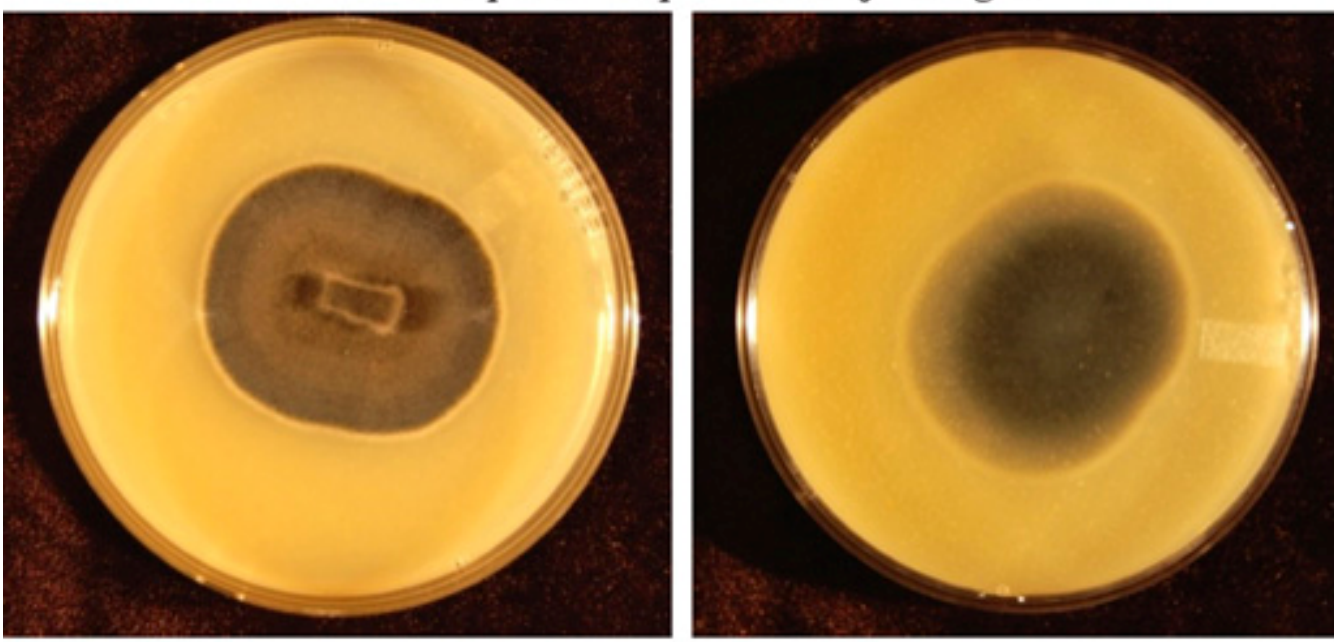

\section{Coleophoma empetri on corn meal agar}
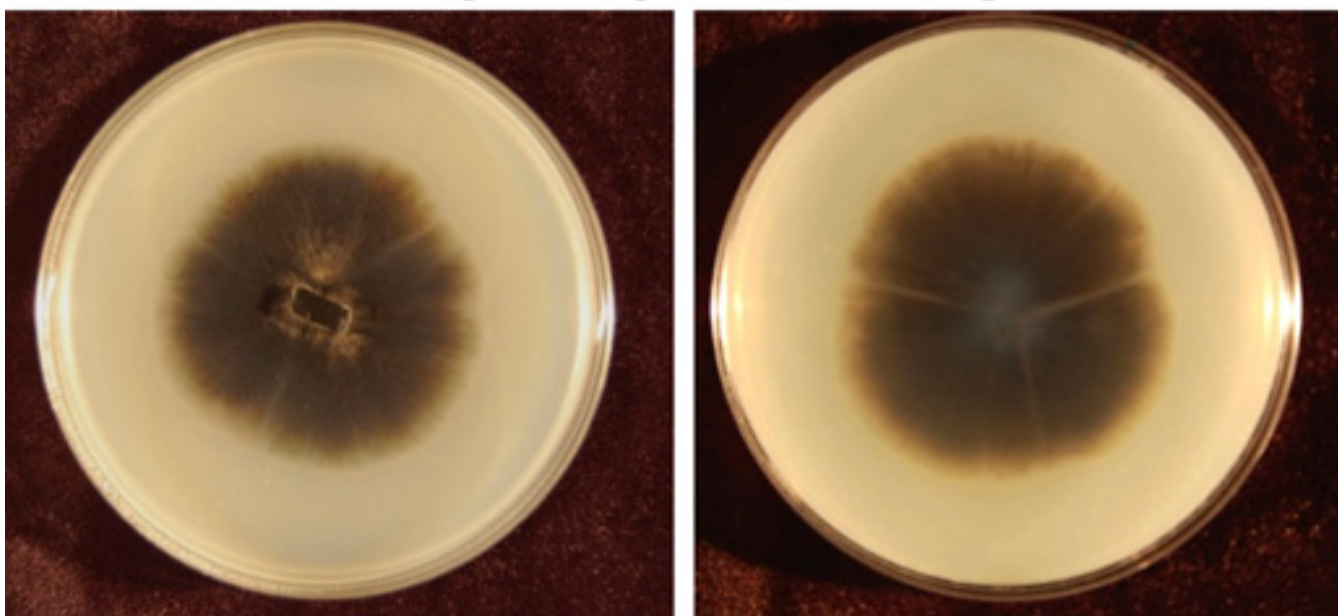

Fig. 2. Coleophoma empetri viewed from above (left) and below (right). 


\section{Colletotrichum acutatum on potato dextrose agar amended with streptomycin sulfate}
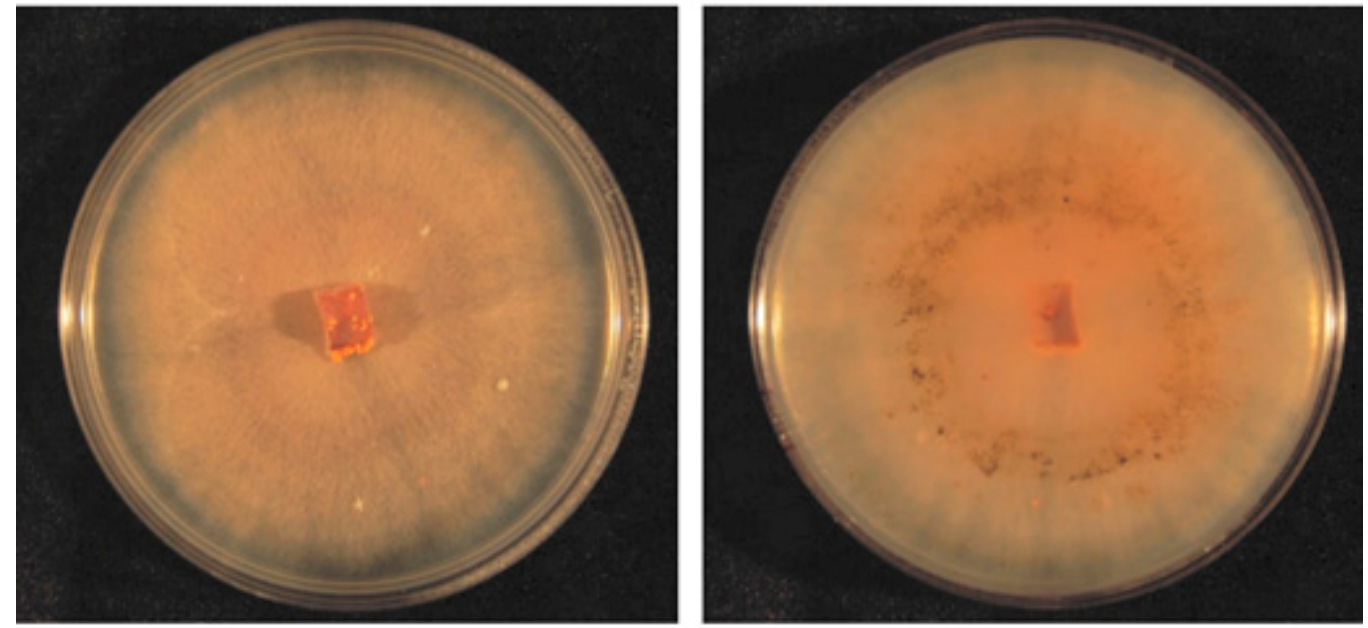

Colletotrichum acutatum on V8 juice agar

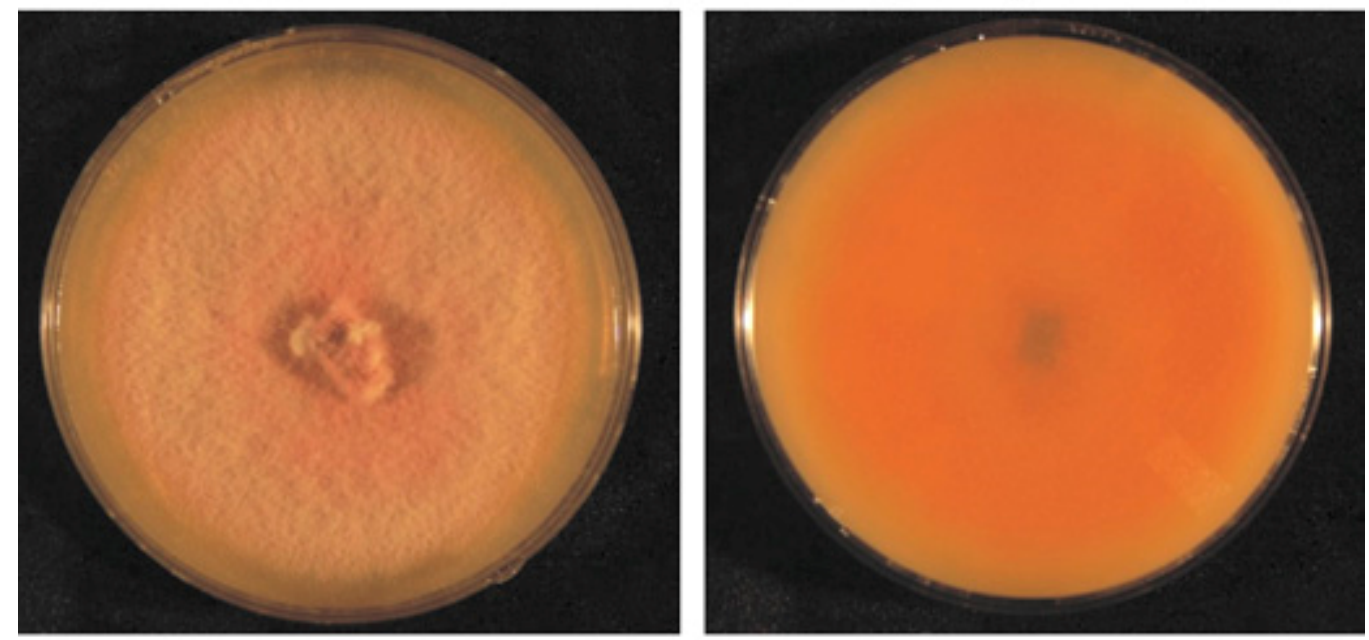

Colletotrichum acutatum on corn meal agar
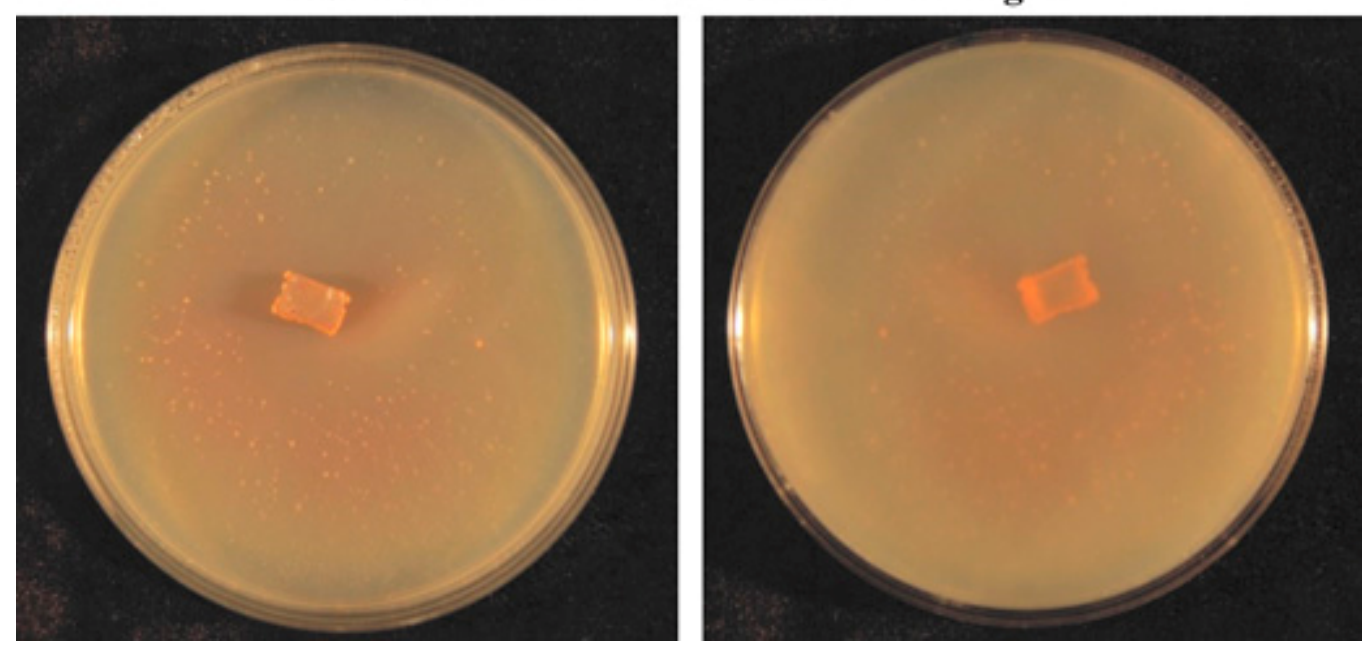

Fig. 3. Colletotrichum acutatum viewed from above (left) and below (right). 
Colletotrichum gloeosporioides on potato dextrose agar amended with streptomycin sulfate
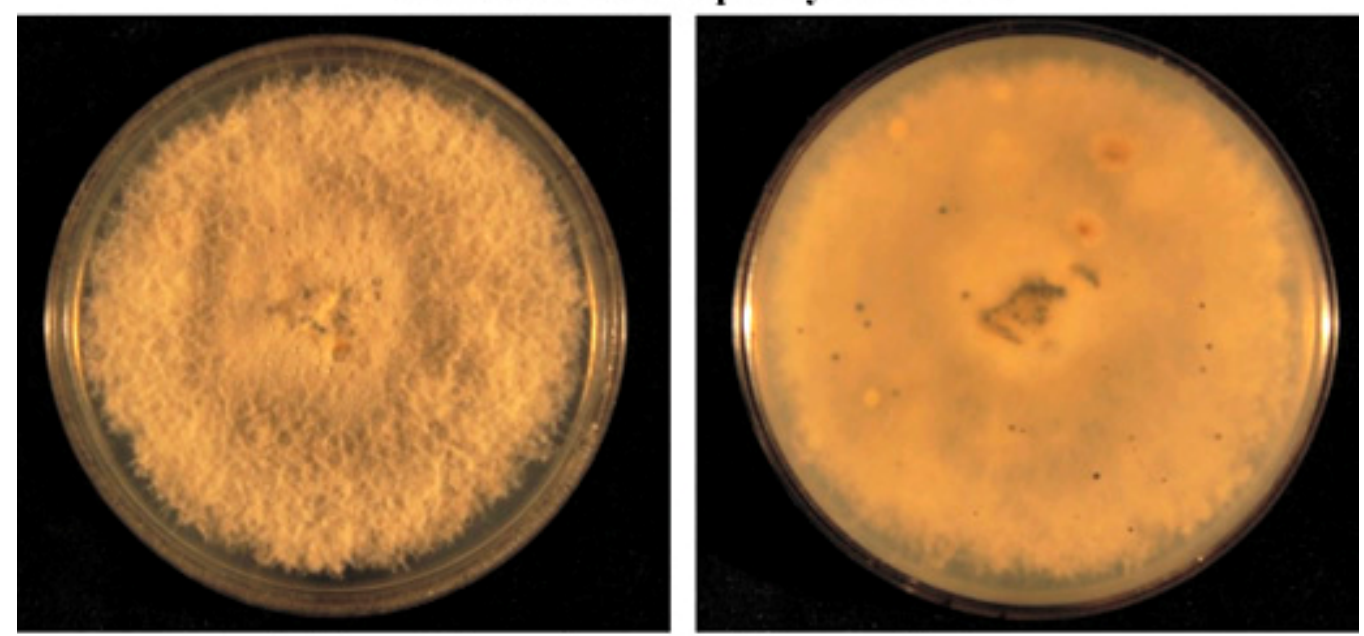

Colletotrichum gloeosporioides on V8 juice agar
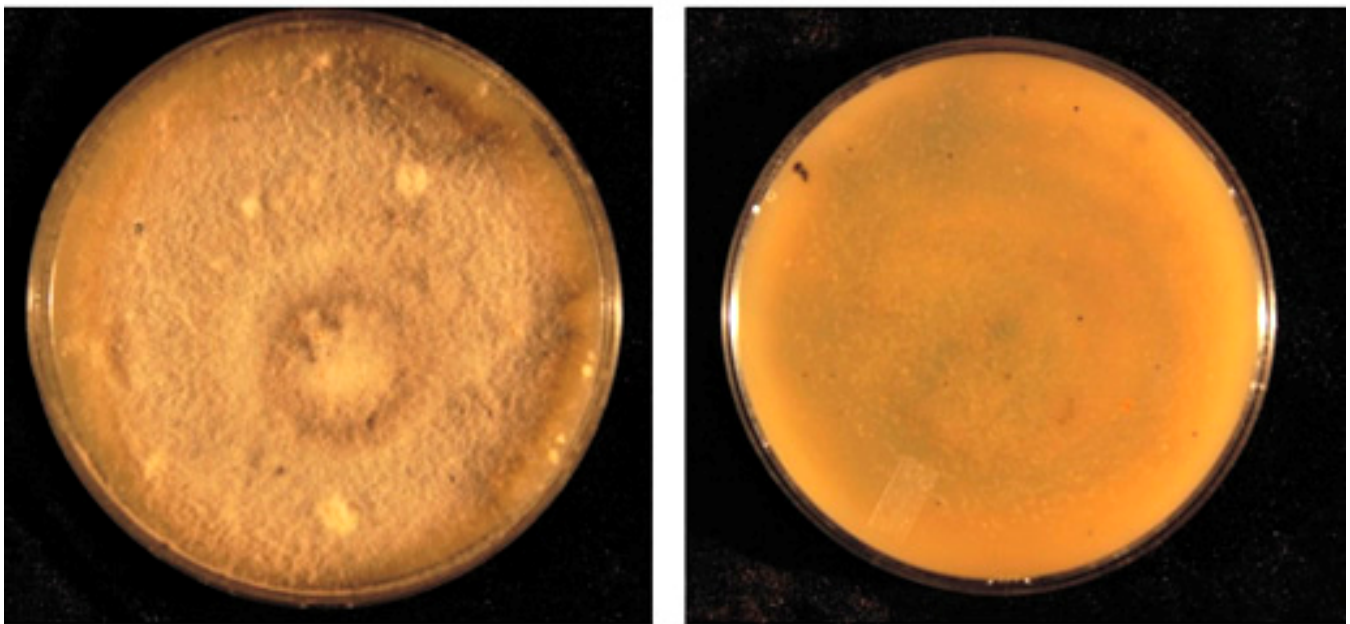

Colletotrichum gloeosporioides on corn meal agar
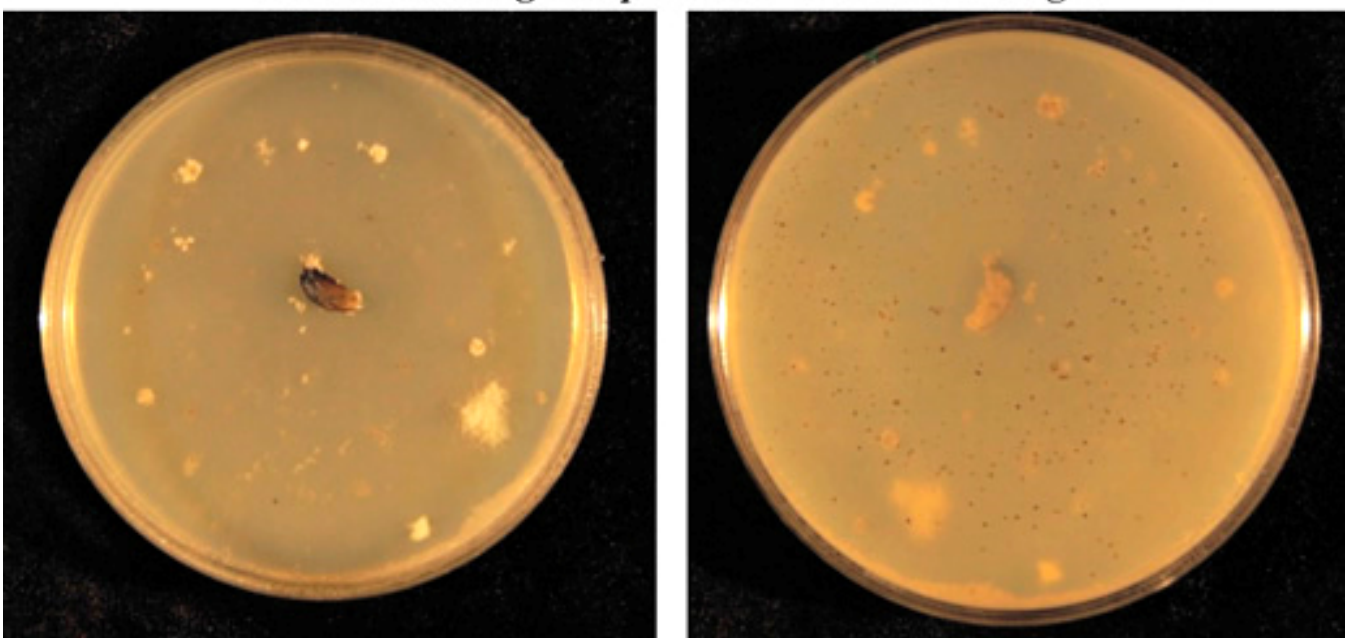

Fig. 4. Colletotrichum gloeosporioides viewed from above (left) and below (right). 
Phomopsis vaccinii on potato dextrose agar amended with streptomycin sulfate
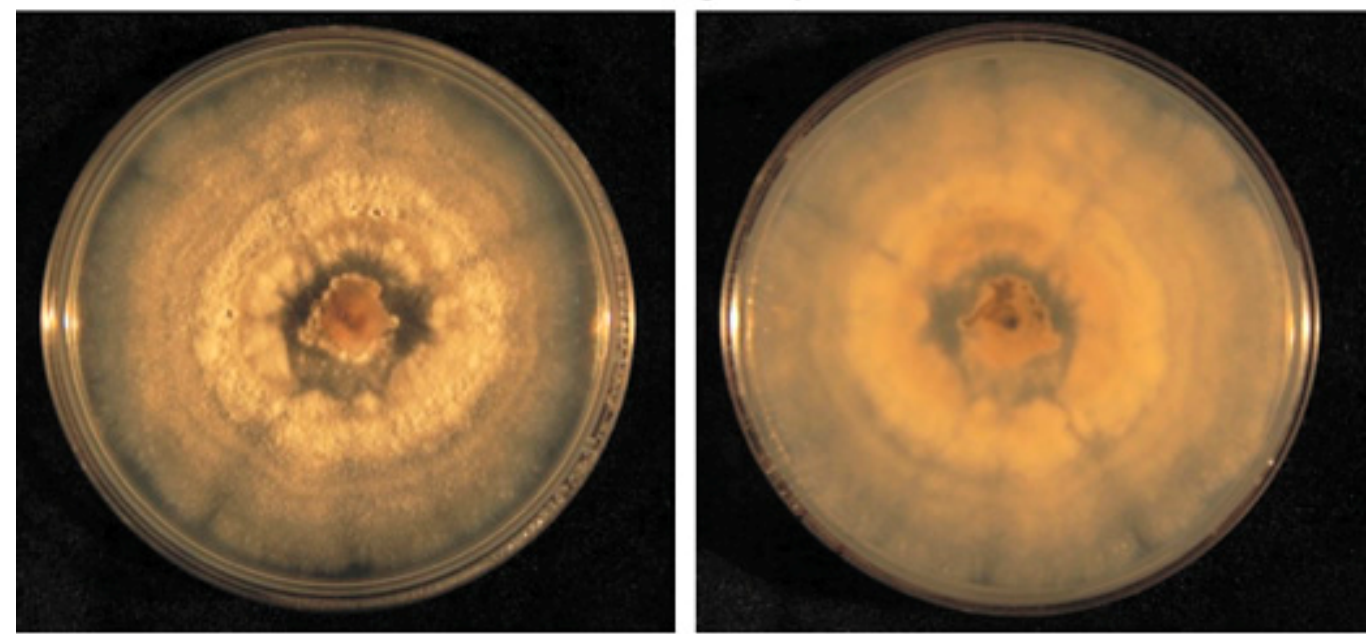

Phomopsis vaccinii on V8 juice agar

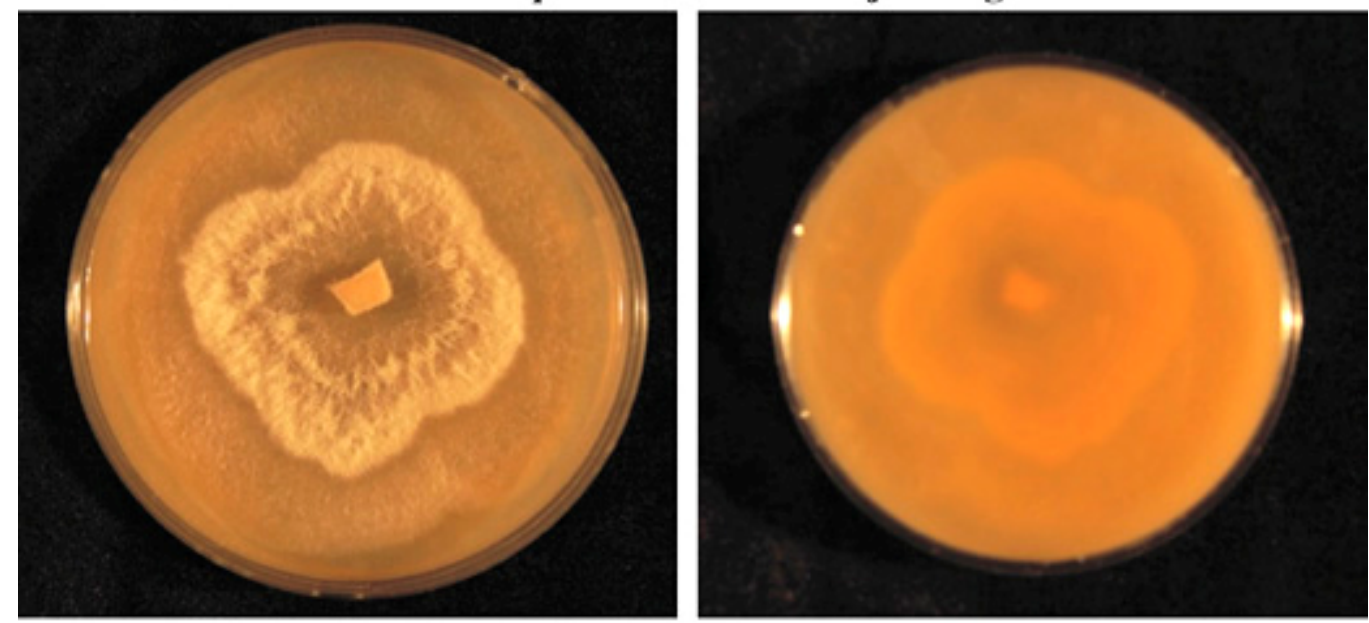

Phomopsis vaccinii on corn meal agar
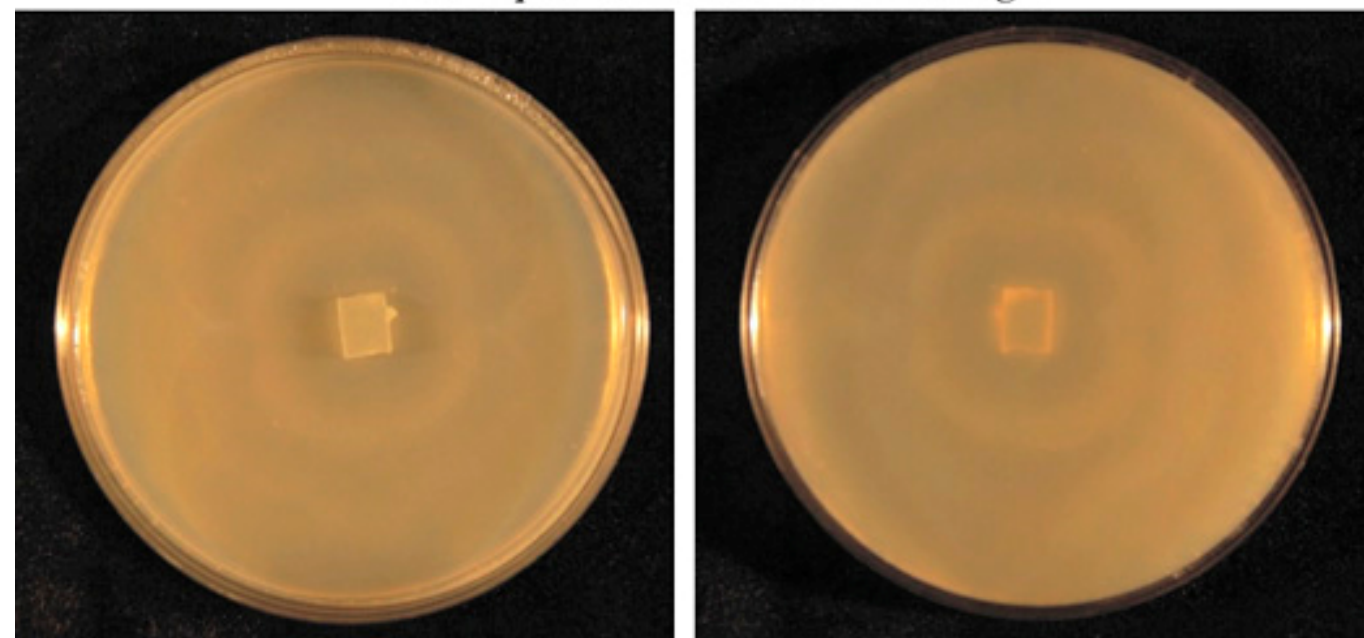

Fig. 5. Phomopsis vaccinii viewed from above (left) and below (right). 
Phyllosticta elongata on potato dextrose agar

amended with streptomycin sulfate
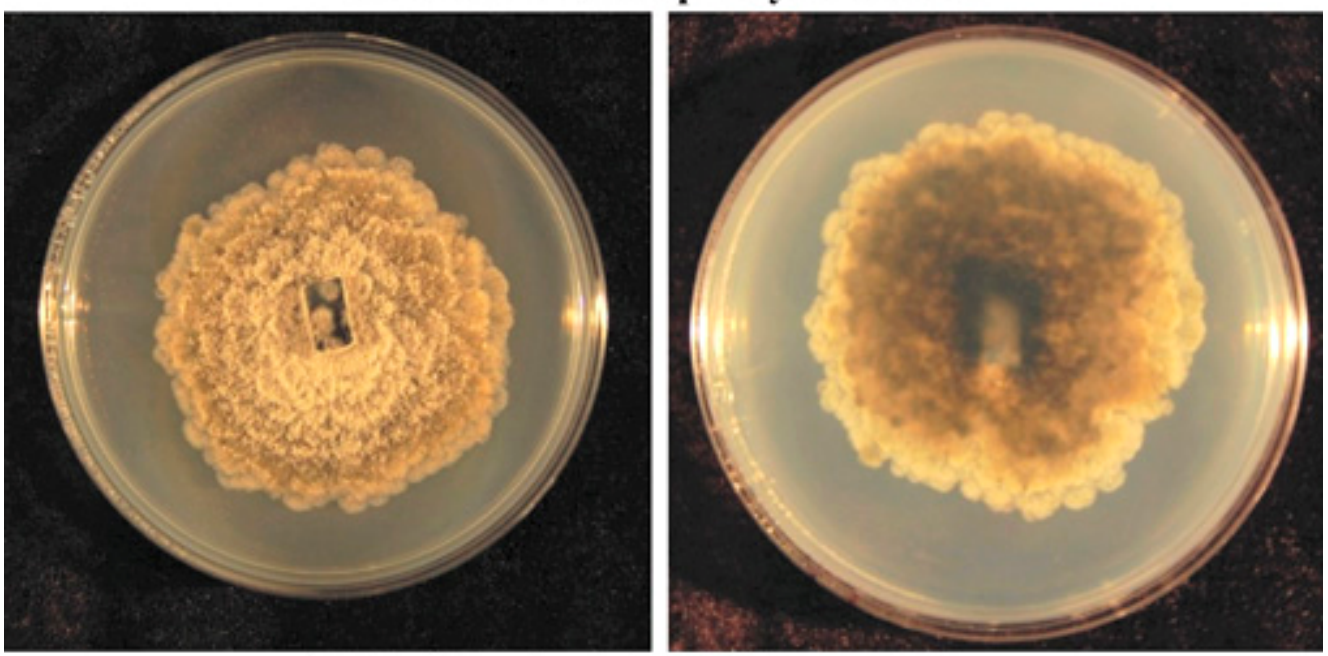

Phyllosticta elongata on V8 juice agar
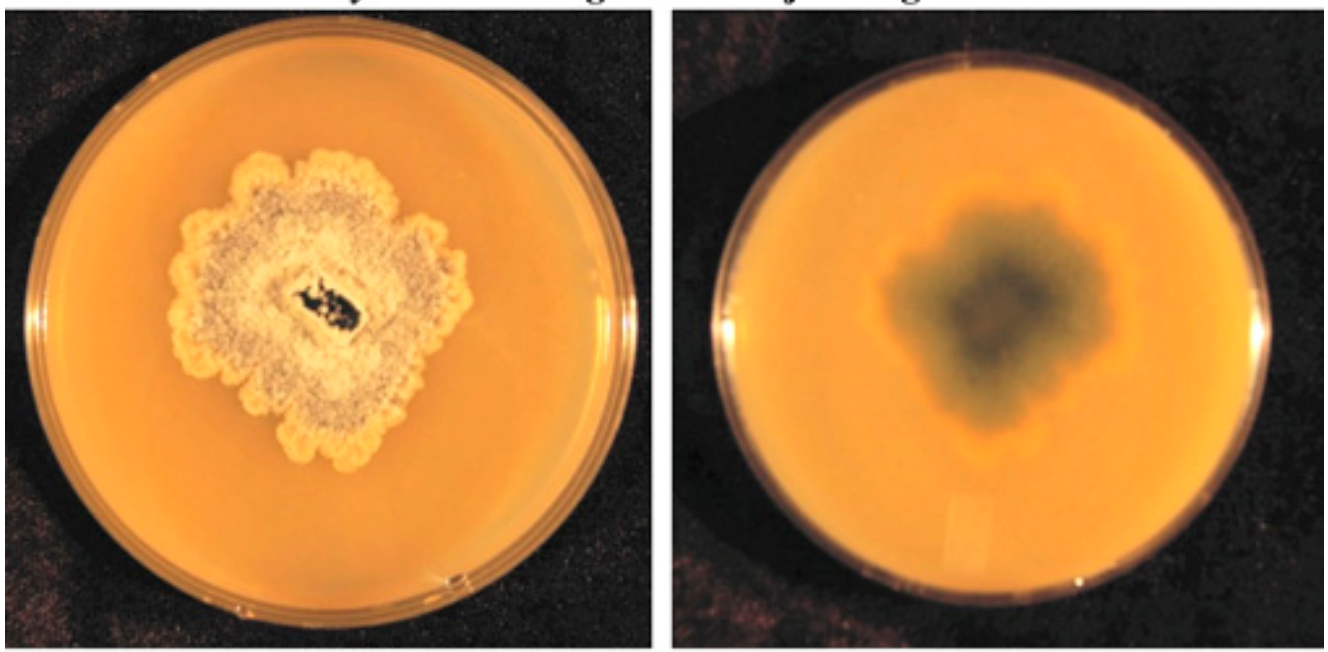

Phyllosticta elongata on corn meal agar
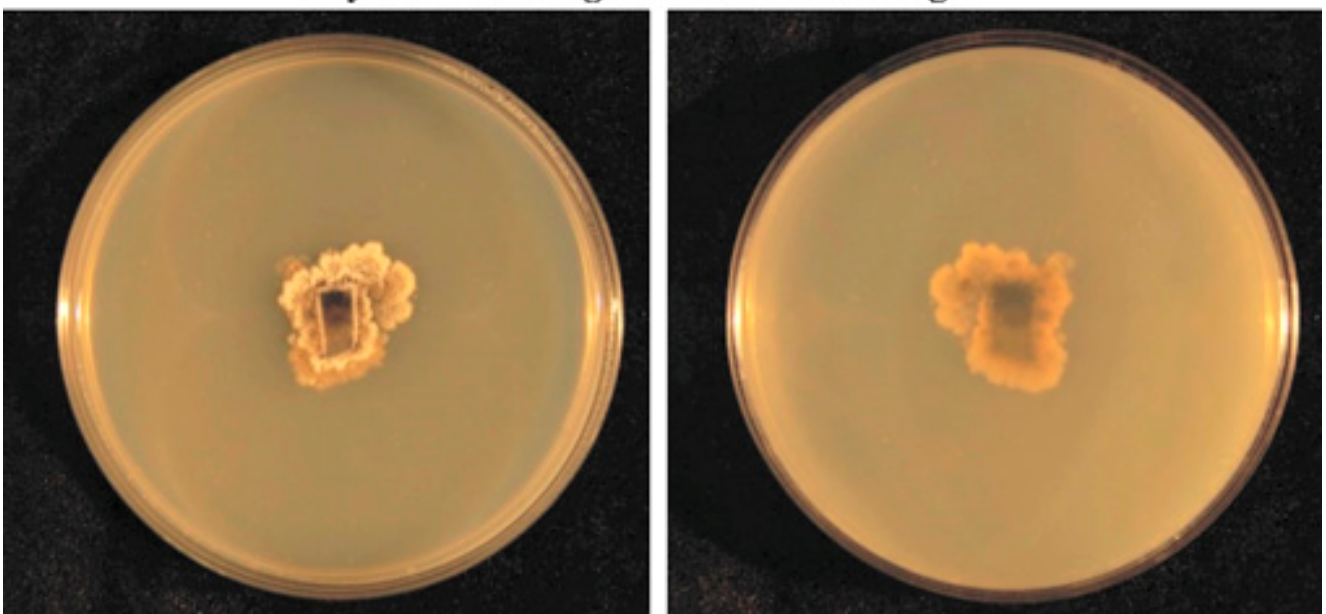

Fig. 6. Phyllosticta elongata viewed from above (left) and below (right). 
Phyllosticta vaccinii on potato dextrose agar

amended with streptomycin sulfate

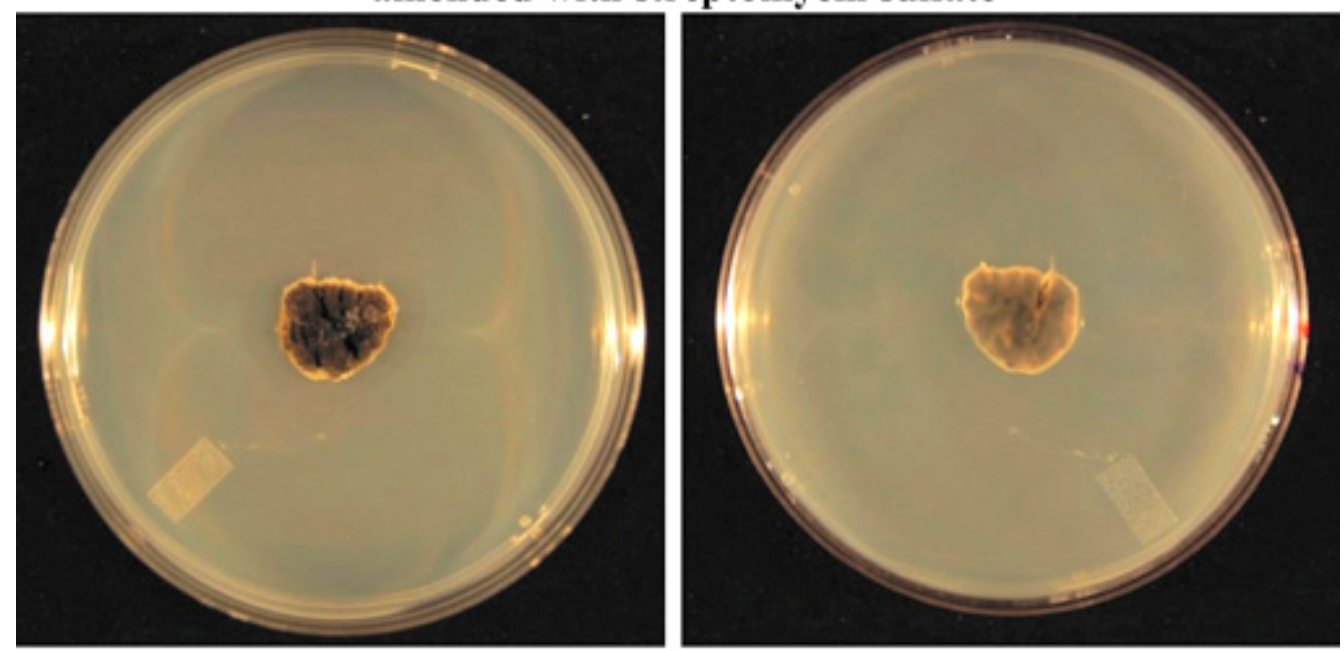

Phyllosticta vaccinii on V8 juice agar

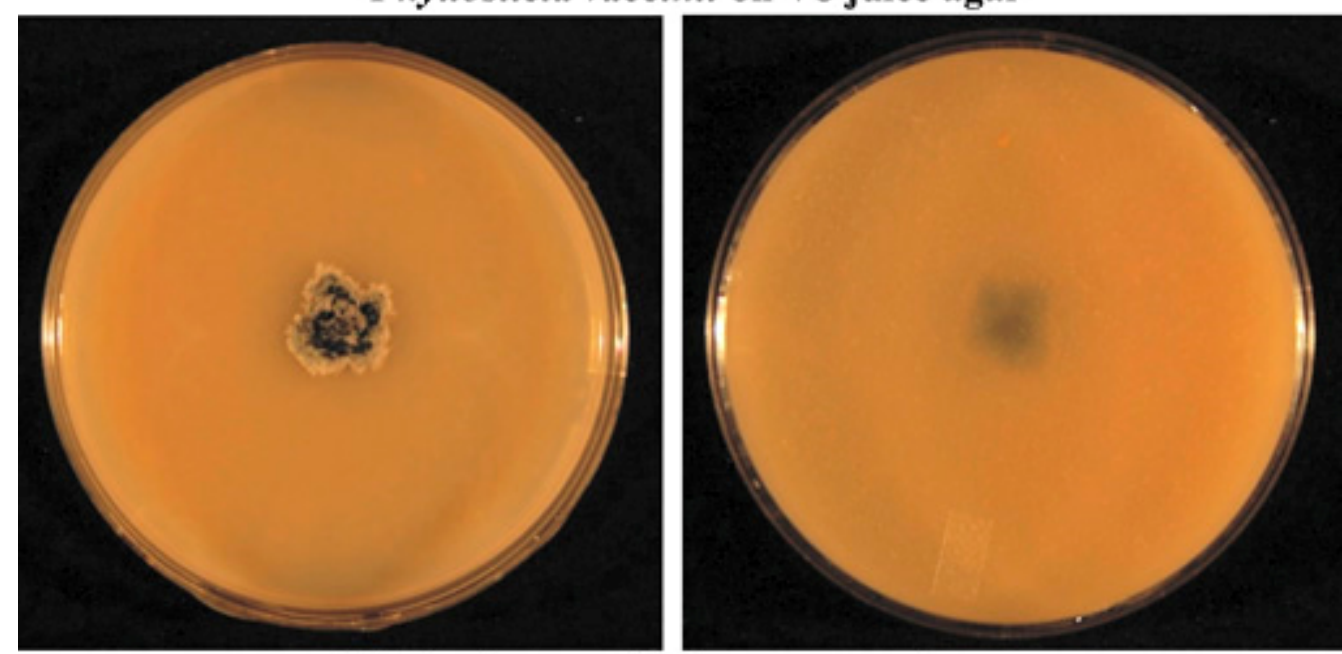

Phyllosticta vaccinii on corn meal agar
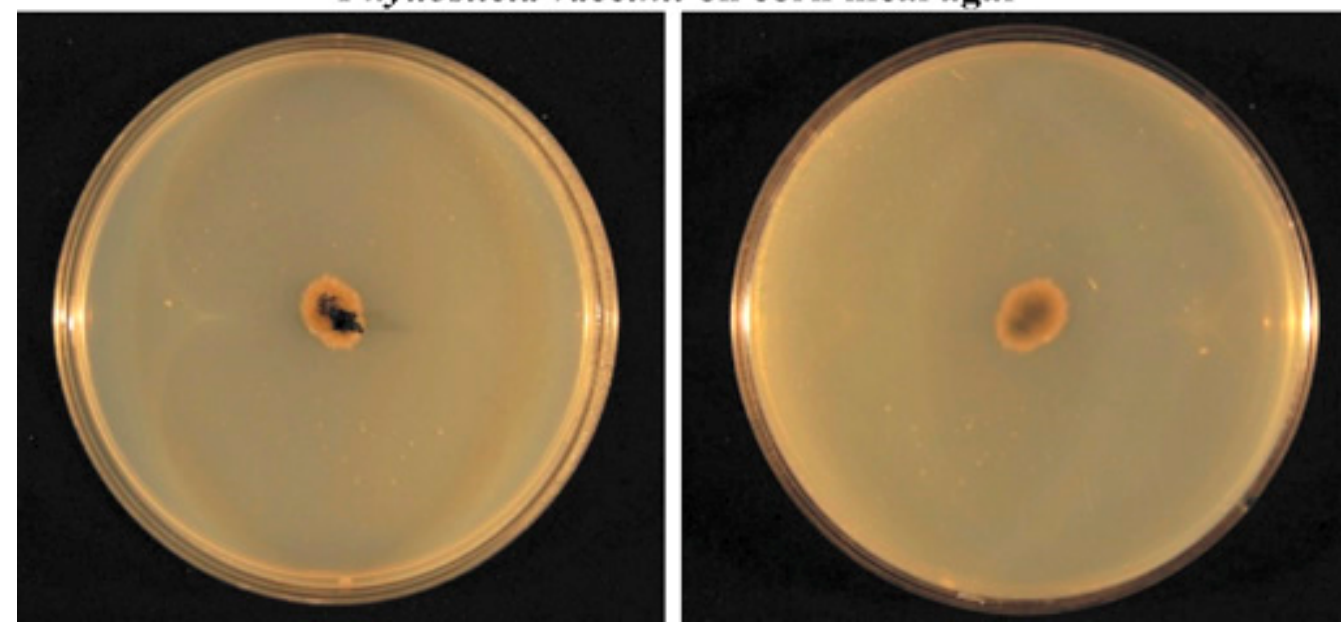

Fig. 7. Phyllosticta vaccinii viewed from above (left) and below (right). 
Physalospora vaccinii (dark strain) on potato dextrose agar amended with streptomycin sulfate

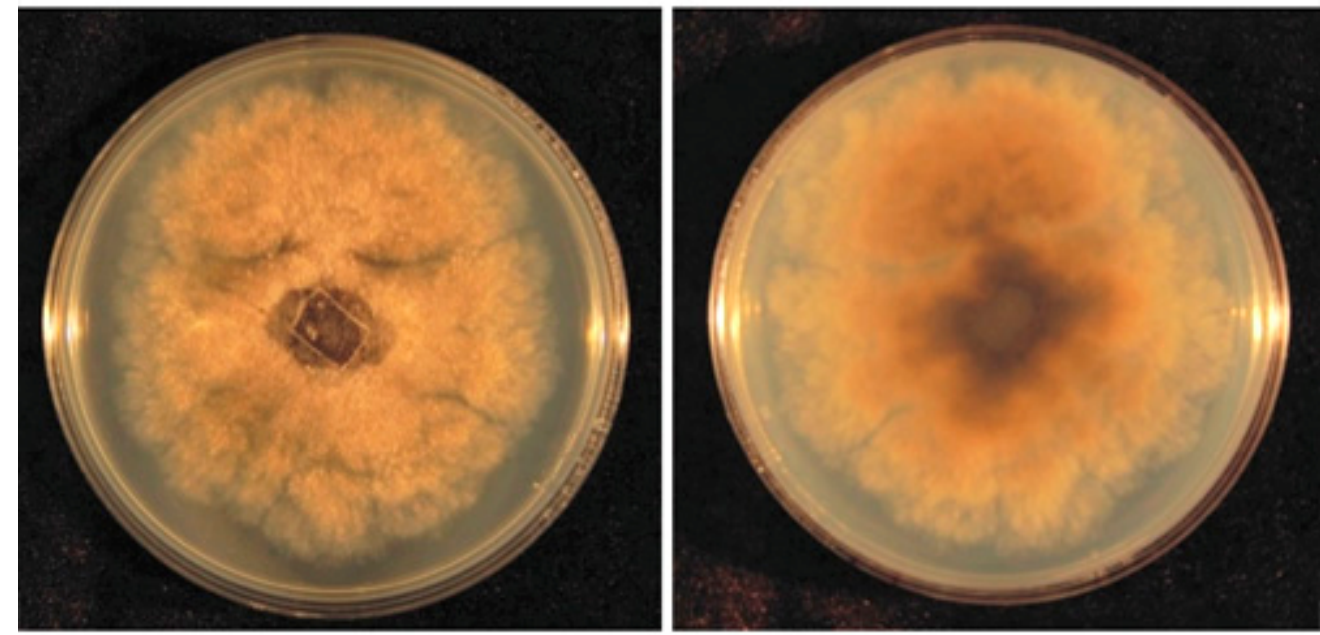

Physalospora vaccinii (dark strain) on V8 juice agar
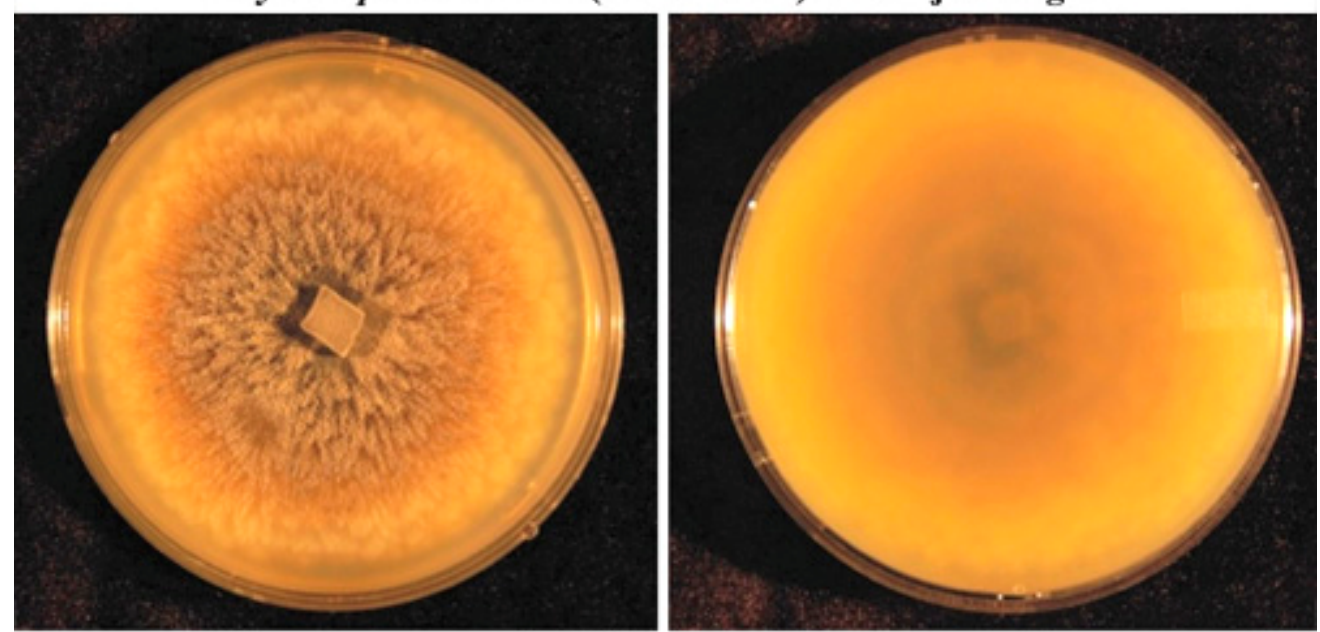

Physalospora vaccinii (dark strain) on corn meal agar
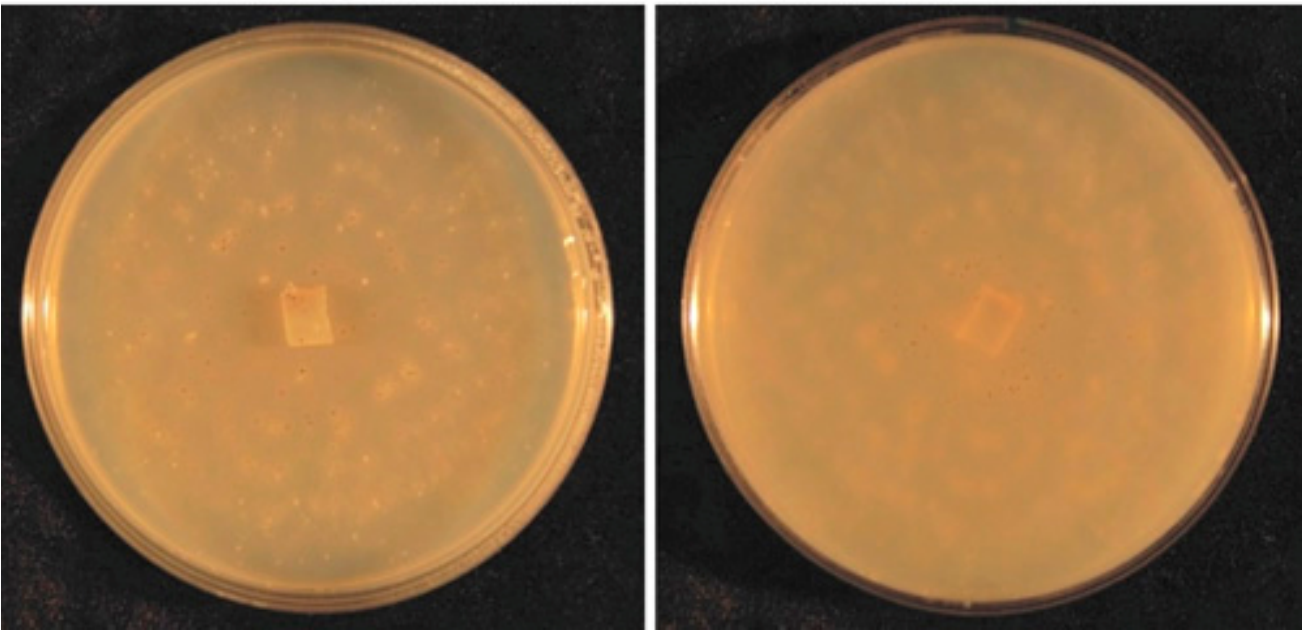

Fig. 8. Physalospora vaccinii (dark strain) viewed from above (left) and below (right). 
Physalospora vaccinii (light strain) on potato dextrose agar amended with streptomycin sulfate

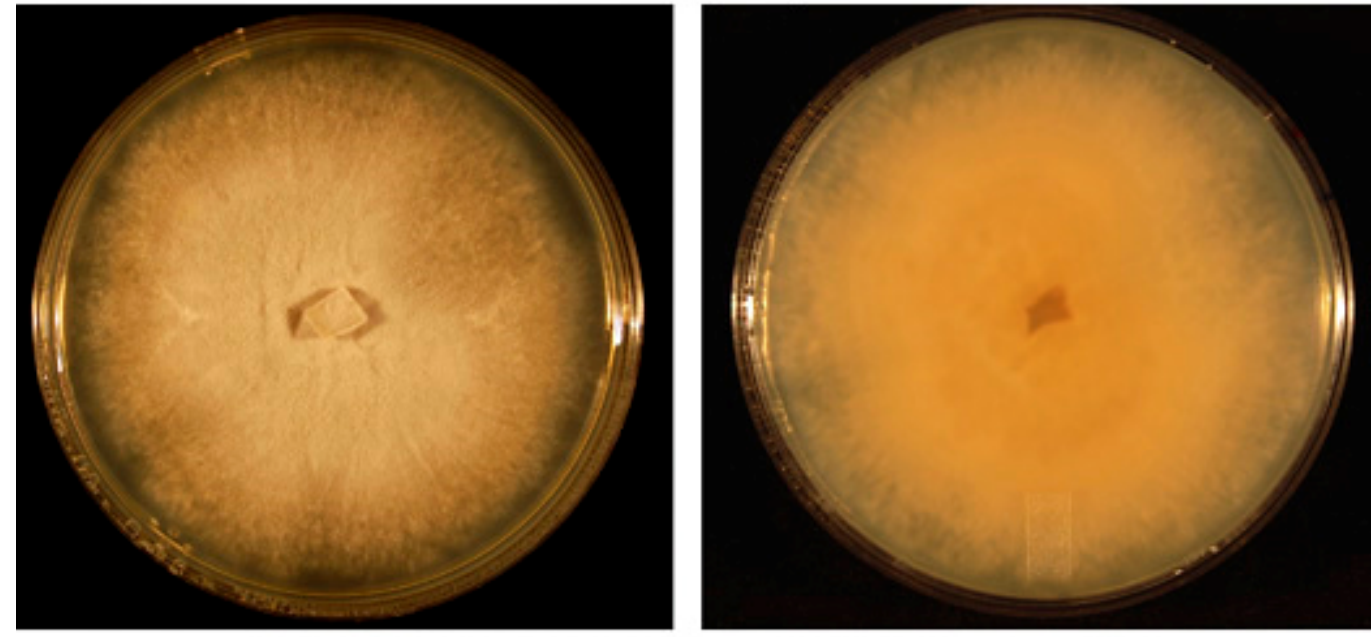

Physalospora vaccinii (light strain) on V8 juice agar
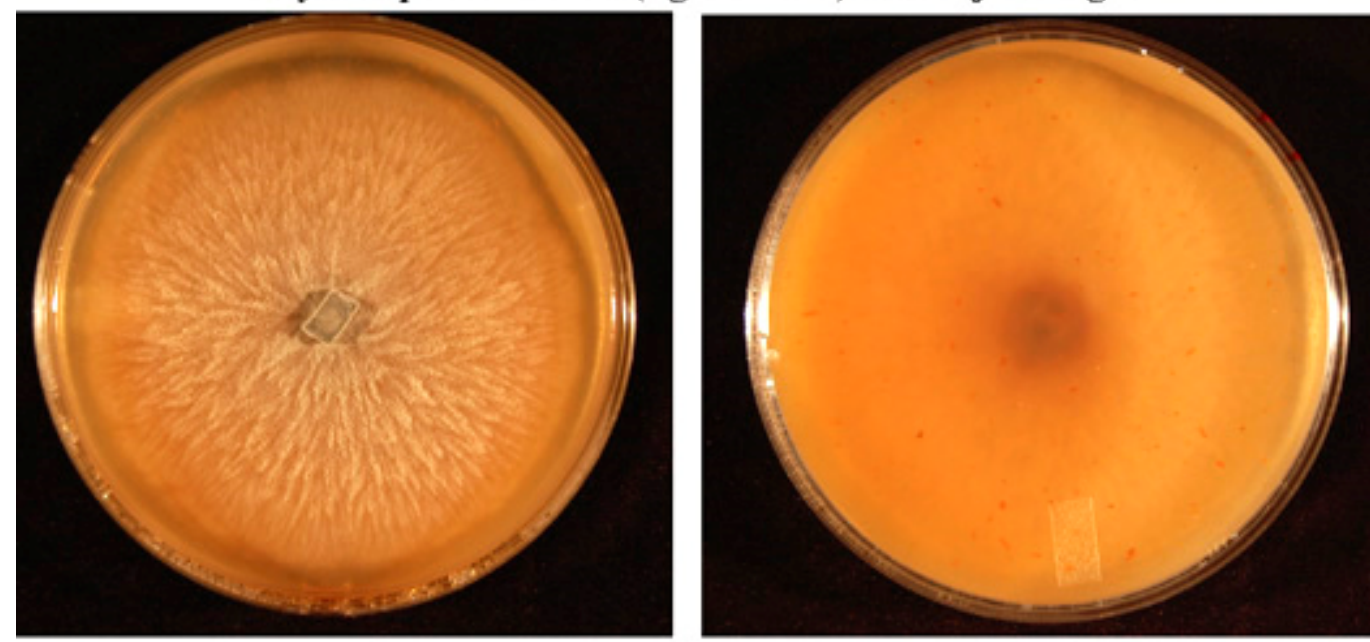

Physalospora vaccinii (light strain) on corn meal agar
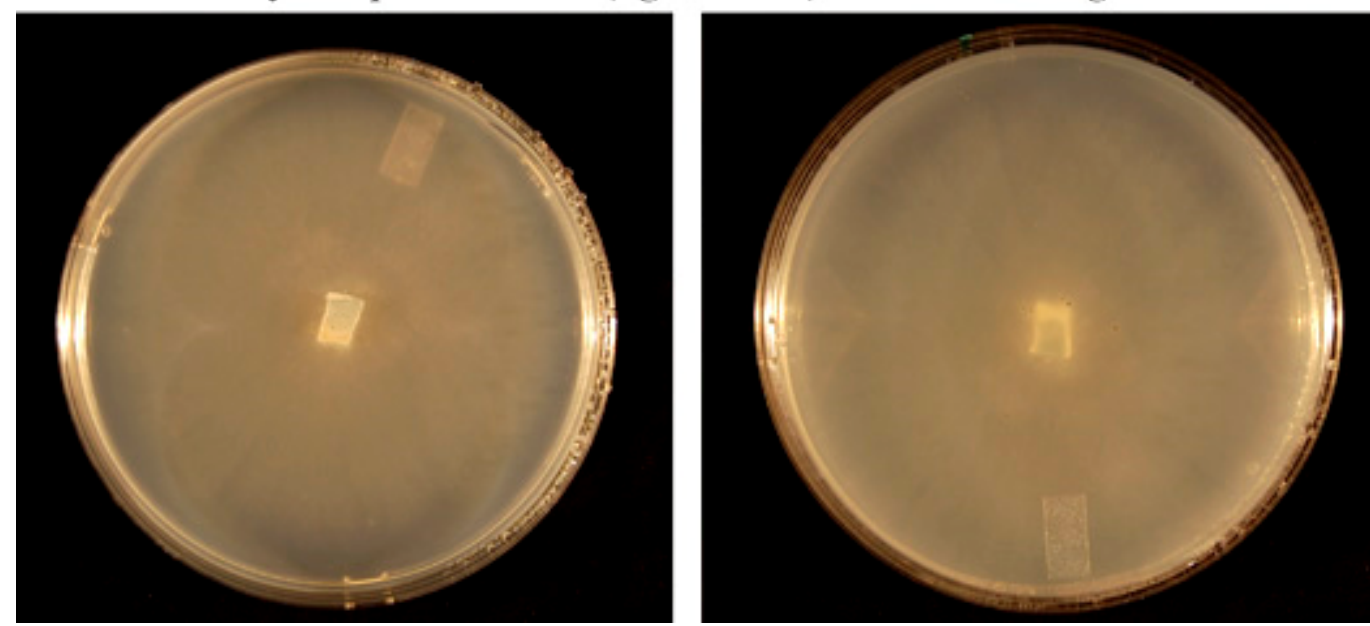

Fig. 9. Physalospora vaccinii (light strain) viewed from above (left) and below (right). 


\section{Acknowledgments}

We thank our cranberry grower cooperators for allowing us to collect samples from their marshes. Funding for this work was provided by Wisconsin Cranberry Board, Inc. and the National Institute of Food and Agriculture, United States Department of Agriculture, under ID number WISo1653.

\section{Literature Cited}

1. Boone, D. M. 1982. End Rot of Cranberry A3196. Univ. of Wisconsin-Extension, Madison, WI.

2. Boone, D. M. 1982. Viscid Rot and Upright Dieback of Cranberry A3195. Univ. of Wisconsin-Extension, Madison, WI.

3. Boone, D. M., and Friend, R. J. 1986. Yellow Rot of Cranberry A3350. Univ. of Wisconsin-Extension, Madison, WI.

4. Boone, D. M., and Schwarz, M. R. 1982. Black Rot of Cranberry A3197. Univ. of Wisconsin-Extension, Madison, WI.

5. Boone, D. M., and Weidemann, G. J. 1986. Early Rot (Scald) of Cranberry and Blast of Blossoms and Young Fruit A3352. Univ. of Wisconsin-Extension, Madison, WI.

6. Brown, K. J. 1982. Physalospora vaccinii and its effect on cranberries in Wisconsin. M.S. thesis. Univ. of Wisconsin, Madison, WI.

7. Caruso, F. L., and Ramsdell, D. C. 1995. Compendium of Blueberry and Cranberry Diseases. American Phytopathological Society, St. Paul, MN.

8. Farr, D. F., and Rossman, A. Y. Fungal Databases, Systematic Mycology and Microbiology Laboratory, USDA-ARS, Washington, DC.

9. McManus, P. S., Caldwell, R. W., Voland, R. P., Best, V. M., and Clayton, M. K. 2003. Evaluation of sampling strategies for determining incidence of cranberry fruit rot and fruit rot fungi. Plant Dis. 87:585-590.

10. Oudemans, P. V., Caruso, F. L., and Stretch, A. W. 1998. Cranberry fruit rot in the Northeast: a complex disease. Plant Dis. 82:1176-1184.

11. Polashock, J. J., Caruso, F. L, Oudemans, P. V., McManus, P. S., and Crouch, J. A. 2009. The North American cranberry fruit rot fungal community: A systematic overview using morphological and phylogenetic affinities. Plant Pathol. 58:11161127. doi: 10.1111/j.1365-3059.2009.02120.x

12. Robideau, G. P., Caruso, F. L., Oudemans, P. V., McManus, P. S., Renaud, M. A., Auclair, M. E., Bilodeau, G. J., Yee, D., Desaulniers, N. L., DeVerna, J. W., and Lévesque, C. A. 2008. Detection of cranberry fruit rot fungi using DNA array hybridization. Can. J. Plant Pathol. 30:1-15.

13. Shear, C. L., Stevens, N. E., and Bain, H. F. 1931. Fungous diseases of the cultivated cranberry. U.S. Dep. Agric. Tech. Bull. 258.

14. Statistics Canada. 2012. Fruit and Vegetable Production. Online. Crops Section, Agriculture Division, Statistics Canada, Ottawa, Ontario, Canada.

15. Stiles, C. M., and Oudemans, P. V. 1997. Cranberry fruit rot pathogens isolated from various cranberry plant tissues over two growing seasons. Phytopathology 87:S94.

16. USDA-NASS. 2012. Quick Stats: Agricultural Statistics Data Base. Online. USDANASS, Washington, DC.

17. Weidemann, G. J., and Boone, D. M. 1982. Taxonomy of Phyllosticta vaccinii (Dothideales, Dothioraceae). Mycologia 74:59-65.

18. Weidemann, G. J., and Boone, D. M. 1983. Incidence and pathogenicity of Phyllosticta vaccinï and Botryosphaeria vaccinii on cranberry. Plant Dis. 67:1090-1093.

19. Zhou, S., and Stanosz, G. 2001. Relationships among Botryosphaeria species and associated anamorphic fungi inferred from the analyses of ITS and 5.8S rDNA sequences. Mycologia, 93:516-527. 